\title{
Peri-procedural Stroke During Percutaneous Closure of Pediatric Atrial Septal Defect
}

\author{
Harsha Basappa ${ }^{1}$, Sachin Rao ${ }^{1}$, Chaitra Doddamadaiah ${ }^{1}$, C.N. Manjunath ${ }^{2}$, Srinidhi Hegde ${ }^{1}$ \\ ${ }^{1}$ Department of Cardiology, Sri Jayadeva Institute of Cardiovascular Sciences, Mysore Branch, Karnataka; ${ }^{2}$ Sri Jayadeva Institute \\ of Cardiovascular Sciences, Bangalore, Karnataka, India.
}

\section{Corresponding Author: \\ Dr. Sachin Rao}

Email: rao.sachin86@gmail.com

This is an Open Access article distributed under the terms of the Creative Commons Attribution License (creativecommons.org/ licenses/by/3.0).

Published

October 8, 2019

November 22, 2019

December 10, 2019

\begin{abstract}
Background: Percutaneous closure of atrial septal defect (ASD) has replaced surgical ASD closure for anatomically suitable ASD. Complication rate of percutaneous procedure is relatively less when compared to surgical closure of ASD. Thromboembolic events leading onto stroke during the procedure is considered extremely rare. Case Report: A 10 year old female who underwent percutaneous ASD device closure had peri-procedure stroke. Cerebral angiogram confirmed acute right middle cerebral artery (MCA) thrombosis. A microcatheter was inserted into occluded MCA, thrombus was disrupted and flow was established. Patient recovered post-procedure. Conclusion: Procedure related thromboembolism is very rare but not unheard of. As there is no consensus on acute procedure related stroke in pediatric population, newer therapeutic explorations may be helpful alternatives.
\end{abstract}

Keywords: Angiography, Cerebral Arteries, Heart Septal Defects, Stroke, Thromboembolism.

\section{Introduction}

Percutaneous closure of atrial septal defect (ASD) is commonly offered as the first option of treatment. The defect should be closed if there is significant left-to-right shunt, defined by a significant right heart enlargement due to volume overload, regardless of symptoms [1,2] or paradoxical embolism [3]. In general, the risks associated with ASD device closure are believed and reported to be relatively low. Safe and effective closure is achieved in at least $80 \%$ of the unselected ASD population. Major complications are device embolization, vascular complications at the puncture site, thrombus on the device, recurrent thromboembolic events, atrial arrhythmias and cardiac erosion or perforation. In a report of ASD closure in adults the complication rate during the procedure was 1\% [4]. Device related thrombosis is very rarely reported. We report a case of peri-procedure thromboembolic stroke in a pediatric ASD device closure despite adequate anticoagulation. To the best of our knowledge this is the first case report of peri-procedural stroke which was successfully managed by thrombus dislodgement.

\section{Case Report}

A 10 year old female presented with history of dyspnea on exertion. Physical examination revealed systolic murmur in pulmonary area and wide fixed $\mathrm{S}_{2}$ split. ECG was suggestive of complete right bundle branch block, right ventricle hypertrophy with strain and sinus tachycardia. Echocardiography showed a large ASD measuring $13 \mathrm{~mm}$ with left to right shunt with dilated right atrium/right ventricle with pulmonary artery systolic pressure $(\mathrm{PASP})=62 \mathrm{~mm} \mathrm{Hg}$. Laboratory findings were normal. Percutaneous device closure was planned. Aspirin was initiated a day prior to the procedure. Under general anesthesia, heparin of 100 
$\mathrm{U} / \mathrm{kg}$ was administered and $16 \mathrm{~mm}$ Life tech ASD occluder was successfully deployed across ASD. Post-procedure, as anesthesia was being weaned, left hemiplegia was noted. Immediate fluoroscopy revealed ASD device in situ. A right common carotid angiogram showed complete occlusion of right middle cerebral artery (MCA) [Fig.1]. A 5F multipurpose catheter was introduced into right common carotid artery over a 0.035 " angled Terumo guide wire. A PTCA 0.014" hydrophilic guide wire was exchanged, passed across the thrombus in MCA, a fine cross coronary microcatheter was introduced over the wire and thrombus was disrupted [Fig.2]. Selective contrast injection showed established flow with TIMI1 flow with residual thrombus [Fig.3]. Patient's consciousness as well as motor functions recovered after a brief time. The activated clotting time (ACT) was $150 \mathrm{~s}$. Additional heparin was given. MRI brain showed acute infarct in right brain [Fig.4]. Post-procedure was uneventful and she was discharged without residual deficits on a dual anti-platelet of aspirin and clopidogrel.

\section{Discussion}

In a study of 1000 patients, incidence of device thrombosis was $2 \%$ after ASD or patent foramen ovale (PFO) closure [5]. Three patients had minor strokes and one experienced a transient ischemia attack (TIA). Thrombus formation was more commonly seen with the CardioSEAL (7.1\%), Star Flex $(5.7 \%)$, and PFO-Star (6.6\%). Surprisingly no thrombosis was noted with Amplatzer device. Clinical predictors of thrombus formation included atrial fibrillation and persistent atrial septal aneurysm. Interestingly, type of anti-thrombotic regimen was not predictive. A recent review of the literature discovered 54 reported cases of device thrombosis, 9 of whom suffered stroke or TIA [6]. The mean time to diagnosis was 5 months and $76 \%$ of the thrombi were left-sided. This underscores the need for indefinite anti-platelet therapy (with dual antiplatelet therapy for 3-6 months), as well as routine echocardiographic surveillance to monitor thrombus formation.
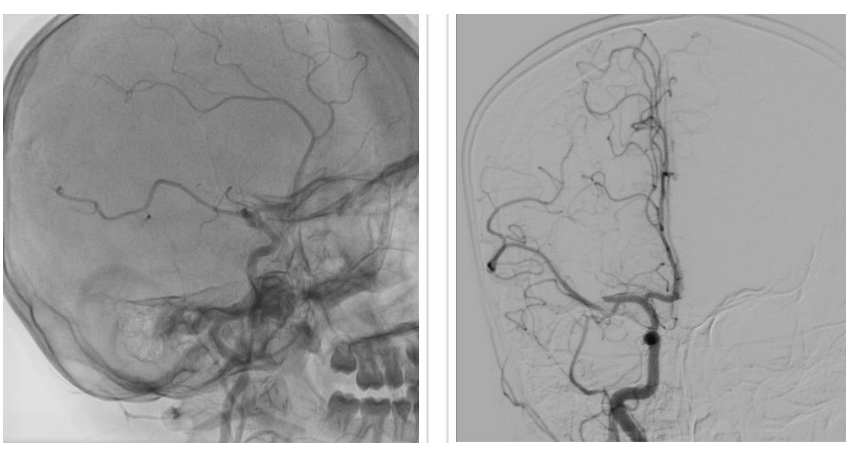

Fig.1: A right common carotid angiogram showed complete occlusion of right $M C A$.

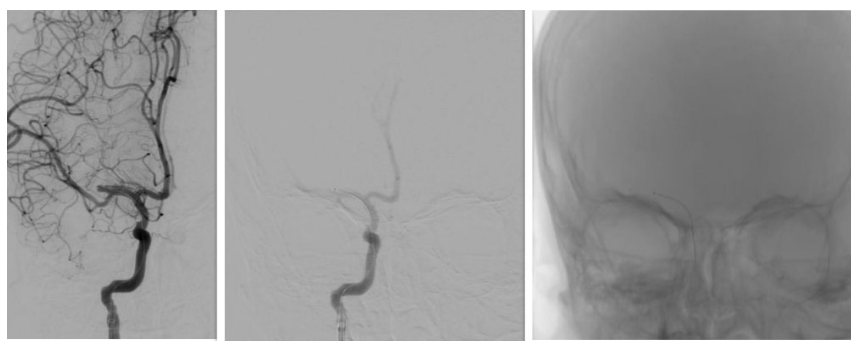

Fig.2: Finecross coronary microcatheter was introduced over the wire and thrombus was disrupted.

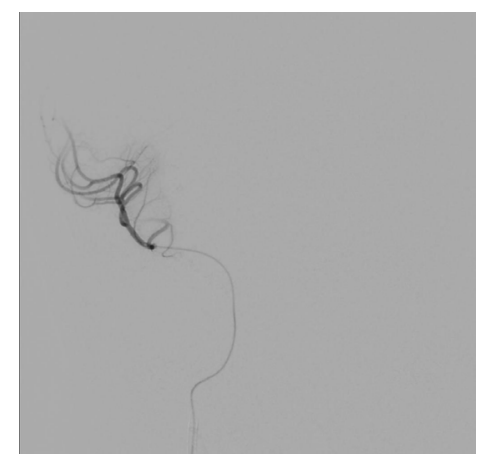

Fig.3: Selective contrast injection showed established flow with TIMI1 flow with residual thrombus.

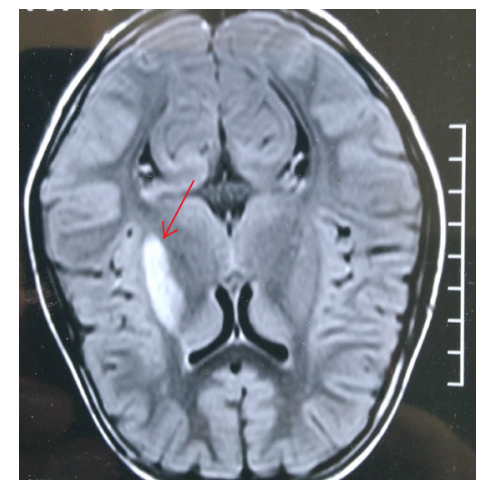

Fig.4: MRI brain showed acute infarct in right MCA territory. 
Structural interventions involve catheter manipulation and longer procedure duration and the slower blood circulation around catheters, both increase the risk of thrombus formation with possible embolization leading to disabling stroke or other organ embolization. Increased thrombin generation soon after the procedure is most likely related to the deposition of fibrin at the interface between blood and the device [7]. While thrombi from the right-sided cardiac chambers remain mostly asymptomatic, even small thrombus from the left atrium can lead to stroke with severe neurologic disability. In case of ASD, paradoxical embolization is a known entity. In our case, most possible explanation of stroke may be thrombus formation inside the delivery sheath. A larger sheath or shorter procedural time might prevent thrombus formation in such instances. Another explanation would be thrombus attached to the device which might have later embolized to cause CVA.

Peri-procedural or post-procedural thrombus formation on the device, which can lead to systemic embolization, is a rare but important complication $[8,10]$. There are very few case reports of stroke during transcatheter closure of ASD device. Most of the thromboses reported are attached to the device per se. Although monitoring of activated clotting time is not routinely recommended during transcatheter closure procedures, we believe that it could help to ensure effective anticoagulation and to avoid thromboembolic events. This case highlights the need of clinical monitoring of the patient post procedure closely, especially in children who are put on general anesthesia.

Ischemic stroke is a rare but wellknown complication of cardiac or neurovascular catheter interventions attributable mostly to embolism [11,13]. Treatment options for acute peri-procedure related stroke include intraarterial thrombolysis, intravenous thrombolysis, mechanical disruption of the thrombus, thrombus aspiration. In adult AIS, there is overwhelming evidence to support intravenous (IV) tissue-type plasminogen activator (tPA) within 4.5 hours of symptom onset and mechanical thrombectomy for large vessel occlusions within 6 hours of symptom onset $[14,15]$. With the delay in diagnosis and lack of treatment protocols in the pediatric population, the efficacy and safety of these treatment strategies are unknown in this population. To date, there are no prospective trials on endovascular treatment in children. Our case is unique, as we tried to dislodge the thrombus with the available coronary micro-catheter to establish flow, which proved to be successful. A novel method even though far from recommendations, was very useful in emergency situation. This case highlights the need for innovative thoughts to handle emergencies.

\section{Conclusion}

Percutaneous closure of atrial septal defect (ASD) is very rarely associated with device/procedure related thrombosis, which may sometimes lead to stroke. Treatment of acute procedure related stroke in pediatric population is difficult as there is no established consensus. Newer therapeutic adventures sometime may prove helpful. Proper monitoring of patients is very essential to identify complications and timely interventions.

Contributors: HB: manuscript writing, and patient management; SR, CD, SH: reviewing the literature, manuscript editing and patient management; CNM: critical inputs into the manuscript and manuscript editing. SR will act as a study guarantor. All authors approved the final version of this manuscript and are responsible for all aspects of the study.

Funding: None; Competing interests: None stated.

\section{References}

1. Butera G, Romagnoli E, Carminati M, Chessa M, Piazza L, Negura D, et al. Treatment of isolated secundum atrial septal defects: impact of age and defect morphology in 1,013 consecutive patients. Am Heart J. 2008;156:706712 .

2. Warnes CA, Williams RG, Bashore TM, Child JS, Connolly HM, Dearani JA, et al. ACC/AHA 2008 guidelines for the management of adults with congenital heart disease: a report of the American College of Cardiology/American Heart Association 
Task Force on Practice Guidelines. J Am Coll Cardiol. 2008;52(23):e143-e263.

3. Therien J, Webb G. Congenital heart diseases in adults. In: Braunwald E, Zipes DP, Libby P, editors. Heart disease: a textbook of cardiovascular medicine. $6^{\text {th }}$ ed. Philadelphia: WB Saunders; 2001. pp. 1592-621.

4. Majunke N, Bialkowski J, Wilson N, Szkutnik M, Kusa J, Baranowski A, et al. Closure of atrial septal defect with the Amplatzer septal occluder in adults. Am J Cardiol. 2009; 103:550-554.

5. Krumsdorf U, Ostermayer S, Billinger K, Trepels $\mathrm{T}$, Zadan E, Horvath K, et al. Incidence and clinical course of thrombus formation on atrial septal defect and patient foramen ovale closure devices in 1,000 consecutive patients. J Am Coll Cardiol. 2004;43:302-309.

6. Sherman JM, Hagler DJ, Cetta F. Thrombosis after septal closure device placement: A review of the current literature. Catheter Cardiovasc Interv. 2004;63(4):486489.

7. Bedard E, Rodes-Cabau J, Houde C, Mackey A, Rivest $\mathrm{D}$, Cloutier S, et al. Enhanced thrombogenesis but not platelet activation is associated with transcatheter closure of patent foramen ovale in patients with cryptogenic stroke. Stroke. 2007;38(1):100-104.

8. Willcoxson FE, Thomson JD, Gibbs JL. Successful treatment of left atrial disk thrombus on an Amplatzer atrial septal defect occluder with abciximab and heparin. Heart. 2004;90(5):e30.

9. Krumsdorf U, Ostermayer S, Billinger K, Trepels T, Zadan E, Horvath K, et al. Incidence and clinical course of thrombus formation on atrial septal defect and patient [sic] foramen ovale closure devices in 1,000 consecutive patients. J Am Coll Cardiol. 2004;43(2):302-309.

10. Butera G, Carminati M, Chessa M, Youssef R, Drago M, Giamberti A, et al. Percutaneous versus surgical closure of secundum atrial septal defect: comparison of early results and complications. Am Heart J. 2006;151(1):228234.

11. Wholey MH, Wholey MH, Tan WA, Toursarkissian B, Bailey S, Eles G, et al. Management of neurological complications of carotid artery stenting. J Endovasc Ther. 2001;8:341-353.

12. Cronqvist M, Pierot L, Boulin A, Cognard C, Castaings L, Moret J. Local intraarterial fibrinolysis of thromboemboli occurring during endovascular treatment of intracerebral aneurysm: a comparison of anatomic results and clinical outcome. Am J Neuroradiol. 1998;19:157-165.

13. Berg-Dammer E, Henkes H, Nahser HC, Kuehne D. Thromboembolic occlusion of the middle cerebral artery due to angiography and endovascular procedures: safety and efficacy of local intra-arterial fibrinolysis. Cerebrovasc Dis. 1996;6:222-230.

14. Campbell BC, Mitchell PJ, Kleinig TJ, Dewey HM, Churilov L, Yassi N, et al. EXTEND-IA Investigators. Endovascular therapy for ischemic stroke with perfusionimaging selection. N Engl J Med. 2015;372:1009-1018.

15. Goyal M, Demchuk AM, Menon BK, Eesa M, Rempel $\mathrm{JL}$, Thornton $\mathrm{J}$, et al. ESCAPE Trial Investigators. Randomized assessment of rapid endovascular treatment of ischemic stroke. N Engl J Med. 2015;372:1019-1030. 